\title{
Synergetic effect of $\mathrm{LaB}_{6}$ and ITO nanoparticles on optical properties and thermal stability of poly(vinylbutyral) nanocomposite films
}

\author{
Hongbo Tang $\cdot$ Yuchang Su $\cdot$ Te Hu \\ Shidong Liu $\cdot$ Shijia Mu $\cdot$ Lihua Xiao
}

Received: 15 April 2014/Accepted: 15 July 2014/Published online: 27 August 2014

(C) The Author(s) 2014. This article is published with open access at Springerlink.com

\begin{abstract}
In this work, different compositions of lanthanum hexaboride $\left(\mathrm{LaB}_{6}\right)$ and tin-doped indium oxide (ITO) nanoparticles were doped into poly(vinylbutyral) (PVB) matrix to prepare $\mathrm{PVB} / \mathrm{LaB}_{6}-\mathrm{ITO}$ nanocomposite (PLINC) films by a solution casting method. X-ray diffraction, Fourier transform infrared spectroscopy, field emission scanning electron microscopy, thermogravimetric analysis (TGA) and ultraviolet-visible-near infrared spectroscopy (UV-vis-NIR) were employed to characterize the PLINCs. The TGA and UV-vis-NIR results reveal that the nanocomposite films possessed outstanding thermal stability. The temperature where $5 \%$ weight loss of the PVB matrix was improved after the addition of $\mathrm{LaB}_{6}$ and ITO particles and the property for blocking near infrared light was also enhanced as compared with the case of pure PVB film.
\end{abstract}

\section{Introduction}

There has been growing demand in recent years to filter out the near infrared (NIR) waves of sunlight that penetrate windows of buildings and vehicles, in accordance with worldwide energy saving and environmental preservation movement $[1,2]$. The focus lies in the NIR light which carries approximately $50 \%$ of solar energy and, at the same time, has no influence on lighting and sight, which are undoubtedly the prime functions of windows. In addition, reduction of solar heat for cars and buildings mediated by the infrared radiation component of energy from the sun

H. Tang $\cdot$ Y. Su $(\bowtie) \cdot$ T. Hu $\cdot$ S. Liu $\cdot$ S. Mu $\cdot$ L. Xiao School of Materials Science and Engineering, Central South University, Changsha 410083, People's Republic of China e-mail: ychsu@csu.edu.cn is desirable, as it would make cooling more efficient. It would reduce energy demand for both air conditioning, and also for powered lighting if daylight is not excessively blocked at the same time [3, 4].

Some materials, such as heat-reflective glasses and sputtered-coating glasses, are promising to meet these demands mentioned above in the future. However, a main hurdle facing them is mass production which is not practical at present, owing to their low yield and the time or energy-consuming process.

Polymer nanocomposite is a kind of novel and fastgrowing material with nano-sized filler being uniformly dispersed in polymer matrix. Polymer nanocomposite possesses enhanced thermal properties, mechanical strength and dielectrics when compared to conventional polymer composites, as a result of strong interactions between polymer matrix and filler [5, 6]. To apply polymeric nanocomposite is a unique approach to reducing heat by blocking near infrared waves while guarantee transmission in visible region for its potential low cost and high productivity.

A well-known material to serve the purpose is represented by the nanoparticles such as tin-doped indium oxide (ITO) [7-10] and lanthanum hexaboride $\left(\mathrm{LaB}_{6}\right)$ [11-13]. They are known for providing highly transparent solar filters to absorb infrared rays. $\mathrm{LaB}_{6}$ is a metal-like plasmonic material, and its nanoparticle with free electrons on surface absorbs NIR of 750-1,300 nm via surface plasmon resonance. ITO is a conductive oxide material, and its nanoparticle absorbs NIR of 1,300-2,500 nm due to inherent band structure [14].

Poly(vinylbutyral) (PVB) is composed of vinyl butyral, vinyl alcohol and vinyl acetate. Properties of PVB can be controlled conveniently by tuning ratios of each monomer in molecular chain where hydrophobic vinyl butyral unit 
provides elasticity, toughness and compatibility with various plasticizers, and hydrophilic vinyl alcohol unit contributes high adhesion to inorganic substrates such as glass. Hence, it is extensively applied in various fields due to the randomly amorphous structure. PVB film possesses similar properties to rubber owing to its intrinsic structure and assistance of plasticizer [15]. Moreover, PVB is a nontoxic, odorless and environment-friendly polymer and thus used as functional materials widely. All in all, PVB is an excellent organic component in organic/inorganic hybrid composite, due to its outstanding compatibility with inorganic materials [16].

$\mathrm{LaB}_{6}$ and ITO nanoparticles have been added into PVB [17, 18], PMMA [19] polymer matrix, respectively, to prepare nanocomposite films for automotive and architectural windows. Yuan et al. [19] have employed modified $\mathrm{LaB}_{6}$ with different sizes in polymethylmethacrylate (PMMA) matrix to investigate effect of particle size on optical properties of $\mathrm{LaB}_{6} / \mathrm{PMMA}$ composites. Schelm and Smith [4] separately prepared $\mathrm{LaB}_{6} / \mathrm{PVB}$ and ITO/PVB composite films, but showed opposite results for glazing applications.

In order to take full advantage of the two kinds of nanoparticles, it is desirable to create $\mathrm{LaB}_{6}-\mathrm{ITO} / \mathrm{PVB}$ composite, so that unique properties of each material can be integrated, and interactions among the three components may bring out some new properties. Moreover, to the best of our knowledge, there is no report that focuses on the integration of the two solid nanoparticles in PVB matrix. Herein, for the first time, our present paper elaborates the preparation and characterization of this new polymer nanocomposite film, which incorporate $\mathrm{LaB}_{6}$ and ITO nanoparticles simultaneously into PVB matrix, and their synergetic effect on optical property and thermal stability of the nanocomposite films.

\section{Experimental}

\subsection{Materials}

PVB (average molecular weight $=35,000-45,000 \mathrm{~g} / \mathrm{mol}$ ), ethanol, dodecylbenzenesulfonic acid (DBS) and polyvinylpyrrolidone (PVP) were purchased from Aladdin Chemical Co., China. Solid particles of ITO and $\mathrm{LaB}_{6}$, with an average diameter of $80-120$ and $20-30 \mathrm{~nm}$, respectively, were provided by Ronghua technology Co. Ltd, China.

\subsection{Characterization techniques}

Crystal structures of $\mathrm{LaB}_{6}$, ITO, pure PVB and nanocomposite films were measured by X-ray diffraction (XRD,
Rigaku, D-MAX2500) using $\mathrm{Cu} \mathrm{K}_{\alpha}$ radiation $(\lambda=$ $0.1542 \mathrm{~nm}$ ) at a scanning rate of $8 \% \mathrm{~min}$ in the $2 \theta$ range of $15-80^{\circ}$. FT-IR spectra were recorded by Nicolet-6700 (USA) spectrophotometer with $4 \mathrm{~cm}^{-1}$ resolution. The $\mathrm{KBr}$ pellet technique was applied for monitoring changes in FTIR spectra of samples in range of 4,000-400 wave numbers $\left(\mathrm{cm}^{-1}\right)$. The vibrational transition frequencies are reported in $\mathrm{cm}^{-1}$. The UV-vis-NIR transmission spectra of the nanocomposite films were investigated by Shimadzu UV3600 (Japan) UV-vis-NIR Spectrophotometer in wavelength scan range of $260-2,400 \mathrm{~nm}$. Thermogravimetric analyses (TGA) were performed on STA449C Simultaneous thermal analyzer at heating rate of $10{ }^{\circ} \mathrm{C} / \mathrm{min}$ from room temperature to $700{ }^{\circ} \mathrm{C}$ under nitrogen atmosphere. Morphology of the nanoparticles (NPs) in PVB matrix was detected by Hitachi-SEM (S-4800, Japan).

\subsection{Preparation of $\mathrm{PVB} / \mathrm{LaB}_{6} / \mathrm{ITO}$ nanocomposite films}

Suspension of the two solid powders in ethanol was conducted separately as following: (1) $\mathrm{LaB}_{6}$ powders (1 wt $\%$ ) and anionic surfactant DBS (0.05 wt $\%)$ were simultaneously dispersed in the solvent. After a few minutes of stirring, a navy blue suspension was obtained and subsequently transferred to planetary ball mill for better homogenization; (2) ITO powder (1 wt $\%$ ) and surfactant PVP $(0.10 \mathrm{wt} \%)$ were treated in the same way.

Then, PVB powder was dissolved in $50 \mathrm{ml}$ of ethanol at $65{ }^{\circ} \mathrm{C}$ for at least $60 \mathrm{~min}$ under continuous stirring. After ITO and $\mathrm{LaB}_{6}$ was dispersed, PVB solution $(10 \mathrm{wt} \%)$ was mixed with the suspension by stirring for $2 \mathrm{~h}$ at room temperature and then ultrasonication for $1 \mathrm{~h}$. Different concentrations of ITO NPs (2, 4 and $6 \mathrm{wt} \%$ ) and $\mathrm{LaB}_{6} \mathrm{NPs}(0.3 \mathrm{wt} \%)$ were applied. The obtained mixtures were stirred for another $6 \mathrm{~h}$ at $65^{\circ} \mathrm{C}$ with assistance of $30 \mathrm{~min}$ of sonication. The resultant suspensions were casted onto glass slides, followed by drying at $40{ }^{\circ} \mathrm{C}$ in an oven for $24 \mathrm{~h}$. Subsequently, fully dried films were separated from the slide. Nanocomposite film was denoted as $X \% \mathrm{LaB}_{6}-Y \%$ ITO, where $X(0.3)$ and $Y(2,4$ and 6) represent mass ratios of $\mathrm{LaB}_{6}$ and ITO in the film, respectively. Thickness of the films was controlled in $0.15-0.3 \mathrm{~mm}$.

\section{Results and discussion}

\subsection{XRD patterns}

Figure 1 illustrates XRD patterns of $\mathrm{LaB}_{6}$ powder, ITO powder, films of pure PVB and $0.3 \% \mathrm{LaB}_{6}-4 \%$ ITO composite. Index processes of diffraction patterns are done 


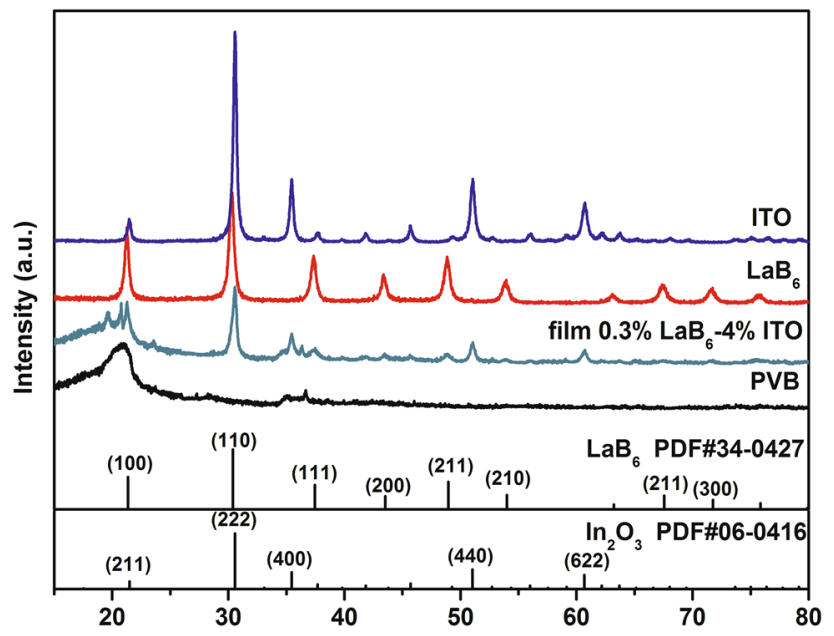

Fig. 1 XRD patterns of nanoparticles of $\mathrm{LaB}_{6}$ and ITO, films of pure PVB and $0.3 \% \mathrm{LaB}_{6}-4 \%$ ITO composite

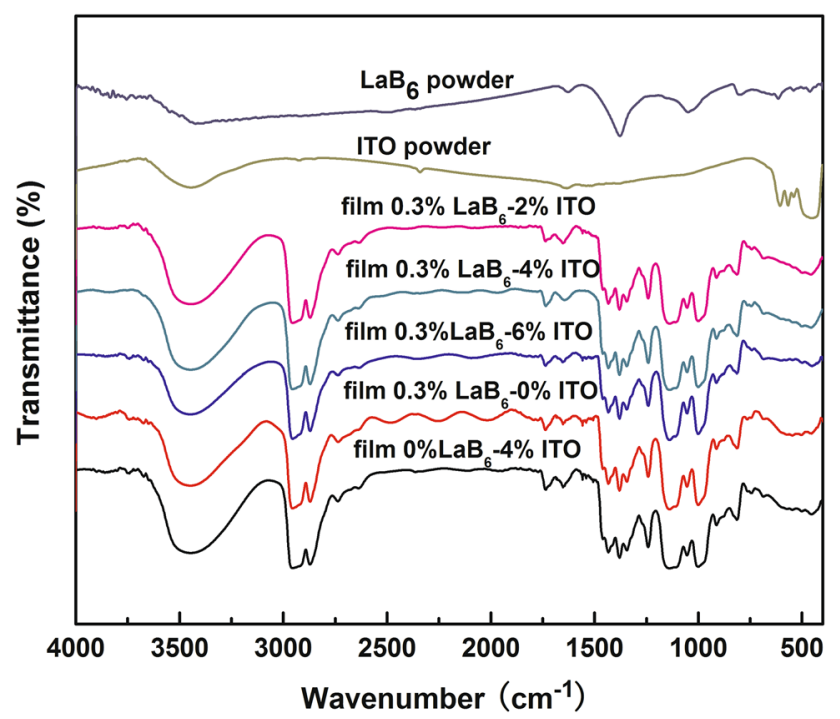

Fig. 2 FT-IR spectra of ITO powder, $\mathrm{LaB}_{6}$ powder and various nanocomposite films

for the solid powders. Many diffraction peaks characteristic of $\mathrm{LaB}_{6}$ and ITO (JCPDS34-0427 and 06-0416, respectively) are noticed in the patterns. The result suggests that these powders were well crystallized with no crystallographic impurity. Two typical peaks appear around $2 \theta=21.5^{\circ}$ and $41.0^{\circ}$ in the pattern of pure PVB film. In the case of $0.3 \% \mathrm{LaB}_{6}-4 \%$ ITO composite film, there remain many inherent diffraction peaks of ITO and $\mathrm{LaB}_{6}$. Although in it typical peaks of PVB are not clearly observed, it still demonstrates considerable impact by two broadened peaks at $2 \theta=21.0^{\circ}$ and $36.0^{\circ}$. The observations imply that ITO and $\mathrm{LaB}_{6}$ remain stable after dispersion in the PVB matrix.

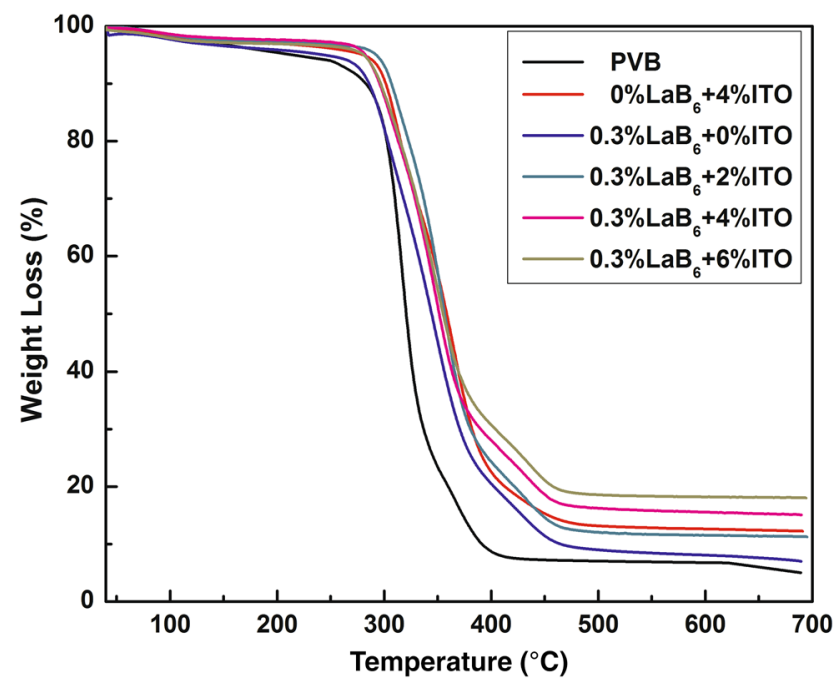

Fig. 3 TGA curves of neat PVB and various nanocomposite films

Table 1 TGA data of neat PVB and various nanocomposite films

\begin{tabular}{|c|c|c|c|}
\hline Samples & $\mathrm{T}_{5}\left({ }^{\circ} \mathrm{C}\right)^{\mathrm{a}}$ & $\mathrm{T}_{10}\left({ }^{\circ} \mathrm{C}\right)^{\mathrm{a}}$ & Char yield $(\%)^{\mathrm{b}}$ \\
\hline Neat PVB & 206 & 280 & 5 \\
\hline Film $0 \% \mathrm{LaB}_{6}-4 \%$ ITO & 280 & 301 & 12 \\
\hline Film $0.3 \% \mathrm{LaB}_{6}-0 \%$ ITO & 234 & 285 & 7 \\
\hline Film $0.3 \% \mathrm{LaB}_{6}-2 \%$ ITO & 281 & 297 & 11 \\
\hline Film $0.3 \% \mathrm{LaB}_{6}-4 \%$ ITO & 284 & 297 & 15 \\
\hline Film $0.3 \% \mathrm{LaB}_{6}-6 \%$ ITO & 292 & 307 & 18 \\
\hline
\end{tabular}

a Temperature where the 5 and $10 \%$ weight loss were recorded by TGA at a heating rate of $10{ }^{\circ} \mathrm{C} / \mathrm{min}$ under a nitrogen atmosphere

b Weight percentage of material left undecomposed after TGA analysis at a temperature of $700{ }^{\circ} \mathrm{C}$ under a nitrogen atmosphere

\subsection{FT-IR spectra}

Figure 2 presents FT-IR spectra of $\mathrm{LaB}_{6}$ powder, ITO powder, $0.3 \% \mathrm{LaB}_{6}-2 \%$ ITO, $0.3 \% \mathrm{LaB}_{6}-4 \%$ ITO, $0.3 \% \mathrm{LaB}_{6}-6 \%$ ITO, $0.3 \% \mathrm{LaB}_{6}-0 \%$ ITO and $0 \%$ $\mathrm{LaB}_{6}-4 \%$ ITO. $\mathrm{H}-\mathrm{O}-\mathrm{H}$ bending region $(1,600-1,700$ $\left.\mathrm{cm}^{-1}\right)$ and $\mathrm{O}-\mathrm{H}$ stretching region $\left(3,100-3,700 \mathrm{~cm}^{-1}\right)$ exist in FT-IR spectra of both the ITO and $\mathrm{LaB}_{6}$ powders, which is attributed to absorption of $\mathrm{H}_{2} \mathrm{O}$ on the surface of the solid particles. In the case of ITO, absorption bands in the region of $400-600 \mathrm{~cm}^{-1}$ are derived from In-O vibration. In the spectra of nanocomposite films, peaks at 1,600-1,700 and $3,100-3,700 \mathrm{~cm}^{-1}$ are originated from bending and stretching vibration of $\mathrm{O}-\mathrm{H}$ in $\mathrm{PVB}$ matrix and ethanol. The absorption peaks at $2,942 \mathrm{~cm}^{-1}$ are characteristic of stretching vibrations of $\mathrm{C}-\mathrm{H}$ and $\mathrm{CH}_{2}$ groups, and those at $1,420 \mathrm{~cm}^{-1}$ correspond to vibration of $\mathrm{CH}_{2}$ bond in $\mathrm{PVB}$ molecule. These spectra are similar in appearance, which could be attributed to low contents and weak absorptions of ITO and $\mathrm{LaB}_{6}$ NPs. 


\subsection{Thermal degradation characteristics}

Figure 3 displays TGA curves of neat PVB and the nanocomposite films. According to the TGA results, thermal degradation of the neat PVB and the various composite films proceeds in two steps: firstly a small and gentle weight loss, then a large and steep one when heated from room temperature to $700{ }^{\circ} \mathrm{C}$. The first weight loss took place in the range of $100-150{ }^{\circ} \mathrm{C}$, which might be caused by evaporation of moisture in PVB matrix and interfacial interactions between them, as shown in Fig. 3. For the neat PVB, the second weight loss in the range of $200-350{ }^{\circ} \mathrm{C}$ is probably due to the polymer dehydration. However, that of the composite films apparently occurs in the range of $250-370{ }^{\circ} \mathrm{C}$, which is slightly higher than that in the case of the neat PVB. In the curve of the neat PVB film, it is noticed that the second weight loss levels off at $400{ }^{\circ} \mathrm{C}$, which corresponds to the decomposition of PVB into carbon black and hydrocarbon under nitrogen atmosphere. However, the same behavior took place even above $450{ }^{\circ} \mathrm{C}$
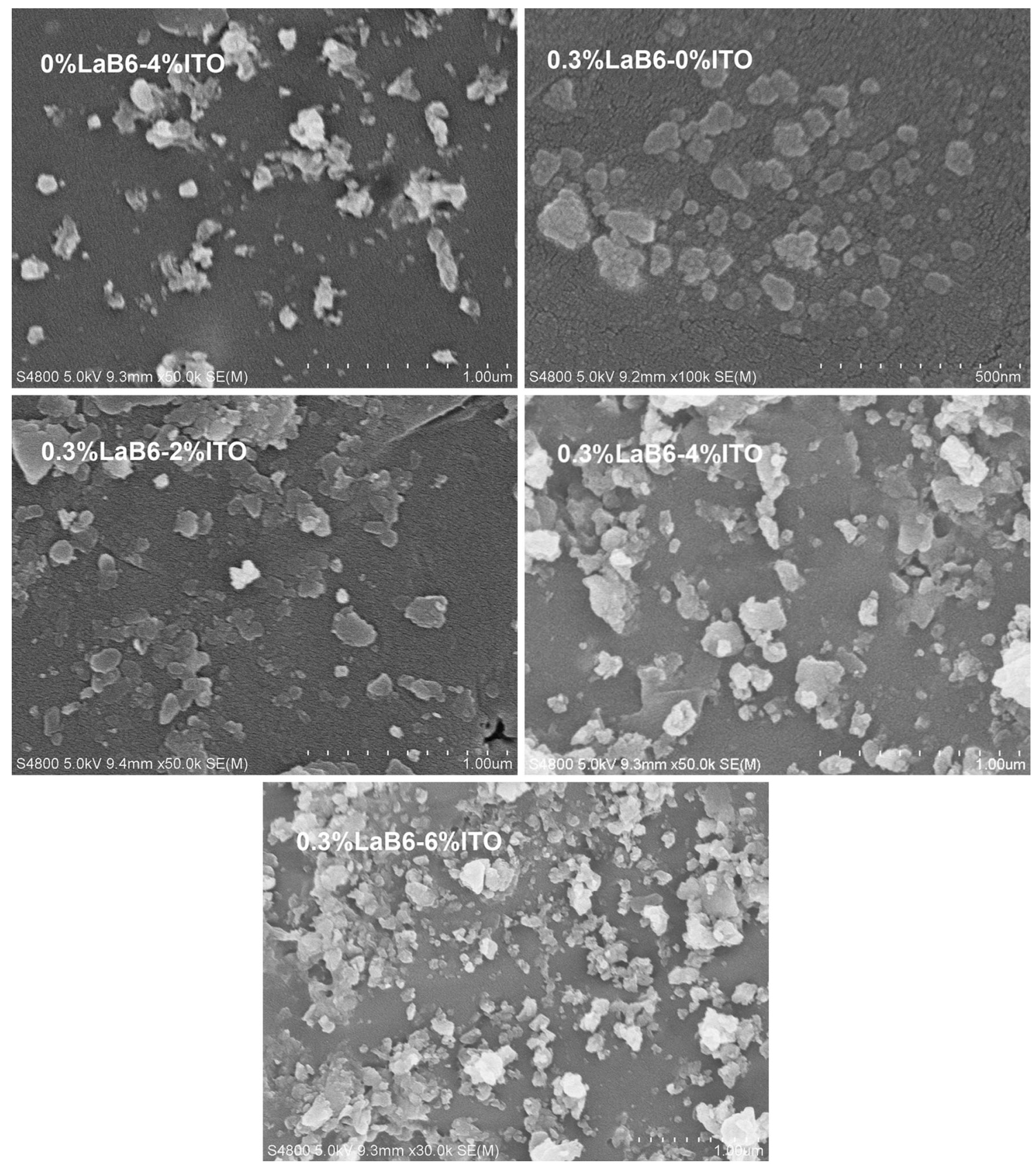

Fig. 4 FE-SEM photographs of the nanocomposite films 
in the nanocomposite samples, and no obvious change is noticed in the behaviors among the five films. This phenomenon is attributed to the carbon black and solid powders in the films.

Table 1 shows the results of the thermal degradation. As expected, the char yields (7-18 wt\%) of the nanocomposite films after heating are higher than that (5 wt $\%)$ of the pure PVB film. Moreover, $\mathrm{T}_{5}$ where $5 \%$ of weight loss occurs shifts from $206{ }^{\circ} \mathrm{C}$ in the case of the neat PVB film to $234{ }^{\circ} \mathrm{C}$ in the case of the composite films only containing $0.3 \mathrm{wt} \%$ of $\mathrm{LaB}_{6}$, even to $281{ }^{\circ} \mathrm{C}$ after adding $2 \mathrm{wt} \%$ of the ITO particles. As the same, $\mathrm{T}_{10}$ is also improved from $280{ }^{\circ} \mathrm{C}$ to at least $285{ }^{\circ} \mathrm{C}$. It should be noted that the addition of ITO and $\mathrm{LaB}_{6}$ into the PVB matrix plays a crucial role in improving the thermal stability of the nanocomposite films.

This improvement on thermal stability might be mainly caused by the ITO particles which act as a barrier to enhance heat insulation and restrain permeability of volatile products in degradation. Moreover, the addition of a small amount of the modified $\mathrm{LaB}_{6}$ into the PVB matrix indeed improves the thermal stability of the composites.

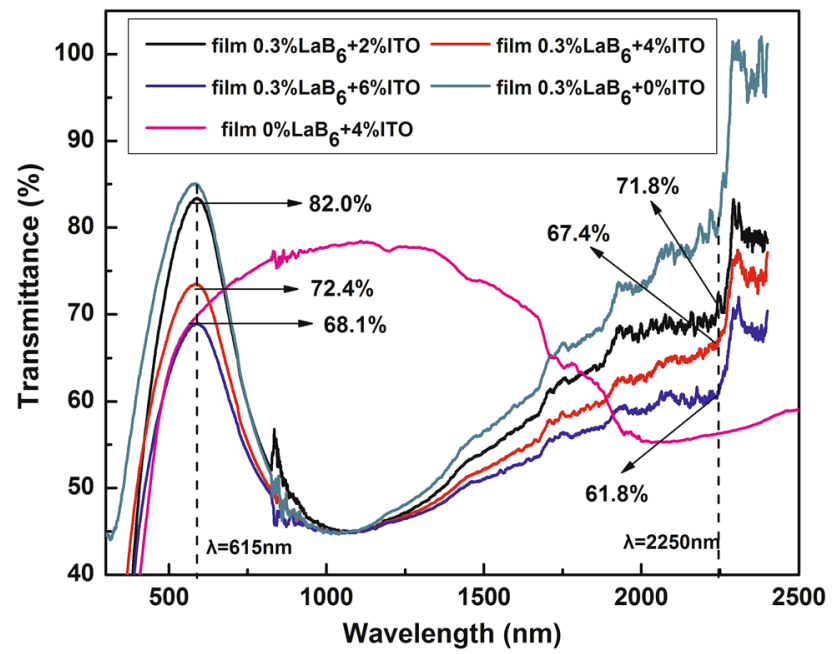

Fig. 5 UV-vis-NIR transmittance spectra of different nanocomposite films
3.4 Field emission scanning electron microscopy (FESEM)

Figure 4 shows morphological images of the nanocomposite films investigated by FE-SEM. In these micrographs, it is observed that ITO and modified $\mathrm{LaB}_{6}$ NPs were homogeneously dispersed in the PVB matrix, owing to their excellent adhesion and strong interfacial bonding to PVB molecules.

\subsection{UV-vis-NIR spectra}

Figure 5 shows transmission spectra of nanocomposite films in region of $250-2,400 \mathrm{~nm}$. It is demonstrated that $\mathrm{LaB}_{6}$ played a key role in absorbing waves between 750 and $1,300 \mathrm{~nm}$, while ITO possessed a remarkable shielding effect against irradiation of 1,300-2,500 $\mathrm{nm}$. Transmittance of these films at 615 and $2,250 \mathrm{~nm}$, as well as average transmittance in the ranges of $380-780$ and $1,000-2,250 \mathrm{~nm}$, is calculated by a formula proposed by Schelm [4] and tabulated in Table 2. It is noted that when the addition of ITO increased from 0 to $6 \%$ transmittance at $615 \mathrm{~nm}$ in visible region decreases from 83.3 to $68.1 \%$, while that at $2,250 \mathrm{~nm}$ in NIR region changes from 81.8 to $61.8 \%$. The average transmittance in the regions presents a similar trend to the transmittance at a single wavelength. In short, content of ITO added in the composites is inversely proportional to transmittance of NIR and vis between 300 and 2,500 $\mathrm{nm}$. As we known, automobile glasses are required to have over $70 \%$ transmittance but as low as possible thermal insulating property. Among five testing samples, film $0.3 \% \mathrm{LaB}_{6}-4 \%$ ITO meets this demand. This result suggests that combination of $\mathrm{LaB}_{6}$ and ITO NPs is promising for application in transparent and thermal insulating materials. However, testing thermal stability of these nanocomposite films under solar irradiation still needs further study.

\section{Conclusions}

The aim of this study was to investigate the synergistic effect of $\mathrm{LaB}_{6}$ and ITO nanoparticles on thermal and

Table 2 Transmittance of various nanocomposite films in Vis-NIR range

\begin{tabular}{lllll}
\hline Sample & $\begin{array}{l}\text { Transmittance } \\
\text { at } 615 \mathrm{~nm}(\%)\end{array}$ & $\begin{array}{l}\text { Average transmittance } \\
(380-780 \mathrm{~nm})(\%)\end{array}$ & $\begin{array}{l}\text { Transmittance } \\
\text { at 2,250 } \mathrm{nm}(\%)\end{array}$ & $\begin{array}{l}\text { Average transmittance } \\
(1,000-2,250 \mathrm{~nm})(\%)\end{array}$ \\
\hline Film 0.3\% LaB 6 + $\%$ ITO & 83.3 & 73.2 & 81.8 & 61.1 \\
Film 0.3\% LaB $+2 \%$ ITO & 82.0 & 69.4 & 71.8 & 57.6 \\
Film 0.3\% LaB $+4 \%$ ITO & 72.4 & 63.8 & 67.4 & 55.0 \\
Film 0.3\% LaB $+6 \%$ ITO & 68.1 & 59.6 & 61.8 & 53.0 \\
Film 0 \% LaB $+4 \%$ ITO & 78.1 & 64.5 & 56.3 & 65.1 \\
\hline
\end{tabular}


optical properties of the nanocomposite films based on PVB. TGA and UV-vis-NIR results indicated that the thermal stability and the property of blocking near infrared spectrum were obviously enhanced after addition of the two types of nanoparticles. The improvement on thermal properties of the composite materials was ascribed to strong hydrogen bonding between $\mathrm{O}-\mathrm{H}$ groups in PVB and oxygen atoms of ITO nanoparticles. FE-SEM results also showed that nanoparticles of $\mathrm{LaB}_{6}$ and ITO were dispersed homogeneously in PVB matrix. The whole process is simple and promising for potential industrialization of the nanoparticles, as well as the optical devices, especially windows of buildings and vehicles.

Open Access This article is distributed under the terms of the Creative Commons Attribution License which permits any use, distribution, and reproduction in any medium, provided the original author(s) and the source are credited.

\section{References}

1. Y.S. Luo, J.P. Yang, X.J. Dai et al., Preparation and optical properties of novel transparent Al-doped-ZnO/epoxy nanocomposites. J. Phys. Chem. C 113, 9406-9411 (2009)

2. Q.B. Ma, Z.Z. Ye, H.P. He et al., Influence of annealing temperature on the properties of transparent conductive and near infrared reflective ZnO: Ga films. Scr. Mater. 58, 21-24 (2008)

3. C.G. Granqvist, I. Hamberg, J.S.E.M. Svensson, Window coatings with selective radiative properties. Ind. Eng. Chem. Prod. Res. Dev. 24, 93-95 (1985)

4. S. Schelm, G.B. Smith, P.D. Garrett, K.W.J. Fisher, Tuning the surface-plasmon resonance in nanoparticles for glazing applications. J. Appl. Phys. 97, 124314 (2005)

5. M. Alexandre, P. Dubois, Polymer-layered silicate nanocomposites: preparation, properties and uses of a new class of materials. Mater. Sci. Eng. R Rep. 28, 1-63 (2000)

6. A.C. Balazs, T. Emrick, T.P. Russell, Nanoparticle polymer composites: where two small worlds meet. Science 17, 1107-1110 (2006)
7. N. Al-Dahoudi, M.A. Aegerter, Wet coating deposition of ITO coatings on plastic substrates. J. Sol Gel. SCI. Technol. 26, 693-697 (2003)

8. H.R. Fallah, M. Ghasemi, A. Hassanzadeh, H. Steki, The effect of annealing on structural, electrical and optical properties of nanostructured ITO films prepared by e-beam evaporation. Mater. Res. Bull. 42, 487-496 (2007)

9. D. Wu, J. Liu, Y. Wang, Enhancing indium tin oxide(ITO) thin film adhesiveness using the coupling agent silane. Appl. Surf. Sci. 256, 2934-2938 (2010)

10. H.T. Liu, X.F. Zeng, X.R. Kong et al., A simple two-step method to fabricate highly transparent ITO/polymer nanocomposite films. Appl. Surf. Sci. 258, 8564-8569 (2012)

11. W. Wang, Y.F. Yuan, L. Zhang, G.H. Min, Annealing effects on properties of $\mathrm{LaB}_{6} / \mathrm{ATO}$ thin films deposited by magnetron sputtering. Ceram. Int. 38, 4313-4318 (2012)

12. F. Jiang, Y.K. Leong, M. Saunders et al., Uniform dispersion of lanthanum hexaboride nanoparticles in a silica thin film: synthesis and optical properties. ACS Appl. Mater. Interfaces 4, 5833-5838 (2012)

13. K. Adachi, M. Miratsu, Absorption and scattering of near-infrared light by dispersed lanthanum hexaboride nanoparticles for solar control filters. J. Mater. Res. 25, 510-521 (2010)

14. H. Harima, O. Sakai, T. Kasuya, A. Yanase, New interpretation of the de Haas-van Alphen signals of $\mathrm{LaB}_{6}$. Solid State Commun. 66, 603-607 (1988)

15. T.S. Valera, N.R. Demarquette, Polymer toughening using residue of recycled windshields: PVB film as impact modifier. Eur. Polym. J. 44, 755-768 (2008)

16. L.J. Chen, J.D. Liao, S.J. Lin, Y.J. Chuang, Y.S. Fu, Synthesis and characterization of $\mathrm{PVB} /$ silica nanofibers by electrospinning process. Polymer 50, 3516-3521 (2009)

17. S. Schelm, G.B. Smith, Dilute $\mathrm{LaB}_{6}$ nanoparticles in polymer as optimized clear solar control glazing. Appl. Phys. Lett. 82, 4346-4348 (2003)

18. Takizawa, et al.: Infrared Cutoff Film. US Patent, No 6, 528, 156 B1, 4 Mar 2003

19. Y.F. Yuan, L. Zhang, L.J. Hu, W. Wang, G.H. Min, Size effect of added $\mathrm{LaB}_{6}$ particles on optical properties of $\mathrm{LaB}_{6} /$ polymer composites. J. Solid State Chem. 184, 3364-3367 (2011) 